\title{
How to Identify and Support Your Anxious Patient
}

David Stonehouse is a Lecturer in Children and Young People's Nursing with the School of Health and Society at the University of Salford.

\section{Abstract.}

This article examines the importance of identifying the anxious patient and how to support them. Recognition of physical signs will be identified. The important areas of giving enough time, developing a therapeutic relationship, always acting in the patient's best interest, involvement of the patient in their care, communication, and information sharing will be discussed. Relevant sections of The Code of Conduct for Healthcare Support Workers and Adult Social Care Workers in England (Skills for Care and Skills for Health, 2013) will be highlighted. If patient's anxiety is not reduced and hopefully removed are they truly being given respect and dignity and the quality of care they deserve?

Key Words: Anxious, Anxiety, Best Interest, Communication, Information Sharing, Stress, Support Workers, Therapeutic Relationship.

\section{$\underline{\text { Introduction }}$}

When a person requires either hospital care or care provided for them within their own home it is natural that there will be a certain amount of fear, trepidation and anxiety. Anxiety is an emotion which occurs "in response to a perceived future threat to either internal or external stimuli" (Askey-Jones and Askey-Jones, 2013:570). All patients are unique and the cause of their anxiety and fear will be personal to them. Recognising this and putting in place supportive strategies is an important part of the therapeutic relationship between the patient and support worker. The patient may be frightened and anxious about what is happening to them, the treatment they are about to receive, their prognosis. They could be worried about who will feed their cat, or collect the children from school, or how they will pay the bills if they are unable to work.

\section{$\underline{\text { Recognition }}$}

When a patient is experiencing anxiety they may have any number of physical signs. These can be observed by the support worker or can be checked through clinical observations or by asking the patient how they are feeling. Box 1 lists some of the most common physical symptoms that can be exhibited by someone with anxiety. 


\section{Box 1}

- a churning feeling in the stomach

- feeling light-headed or dizzy

- pins and needles

- feeling restless or unable to sit still

- headaches, backache or other aches and pains

- faster breathing

- a fast, thumping or irregular heartbeat

- sweating or hot flushes

- problems sleeping

- grinding teeth, especially at night

- nausea

- needing the toilet more or less often

- changes in patients sex drive

- experiencing panic attacks.

(Mind, 2013)

However, even though a patient does not show any outward signs of anxiety does not mean they are not experiencing it. They may appear to be completely calm on the outside, but inside they could be in turmoil. Some patients may be withdrawn and quiet. Being sensitive and open to how your patient is feeling and being aware of the potential for anxiety to be present are important.

$\underline{\text { Time }}$

Giving patients the time to talk and express their feelings and anxiety is one key strategy. Patients need to feel that the support worker has the time to listen to them. That their concerns and worries are being taken into account and addressed. However, time is often at a premium, with increasing workloads and staff shortages. In some areas for example day surgery, the turnover of patients is very fast and therefore patients may feel rushed and unable to express their concerns and worries.

\section{Developing a Therapeutic Relationship}

Mitchell (2005) identifies the importance of what he calls the 'therapeutic use of self,' in reducing patient's anxiety. Sharples (2013) states that the required components of developing a therapeutic relationship include genuineness, empathy, positive regard and warmth, rapport and trust. The use of touch and comforting words can also help to give support. Through the close proximity of the support worker, offers reassurance and support. This links closely with making time for the patient and being physically there for them.

\section{Best Interests}

Within The Code of Conduct for Healthcare Support Workers and Adult Social Care Workers in England (Skills for Care and Skills for Health, 2013) the best interest of the patient is promoted. Section 2.1 states that the support worker must "always act 
in the best interests of people who use health and care services." Section 2.2 says to "always treat people with respect and compassion." Section 2.3 goes on to state that you must "put the needs, goals and aspirations of people who use health and care services first, helping them be in control and to choose the healthcare, care and support they receive." Through recognising and meeting a person's needs in respect to anxiety the support worker will be acting in their best interests, treating them with respect and compassion and helping them to take back control of what is happening to themselves.

\section{Involvement}

The Code of Conduct for Healthcare Support Workers and Adult Social Care Workers in England (Skills for Care and Skills for Health, 2013) states in section 3.4 that support workers must "work openly and cooperatively with" their patients and families/carers treating them with respect. This highlights that the support worker needs to involve the patient in their care. This involvement needs to be negotiated. Different patients will ask or need different levels of involvement. Mitchell (2011) states that by giving patients choice allows them to feel more in control and this can reduce their anxiety. This control can be quite minor or merely perceived as choices by the patient. For example asking the patient which arm they would prefer a blood sample to be taken from, or allowing a patient to stay dressed until nearer the time for their operation, thus allowing the patient to feel more in control of what is happening to them.

\section{Communication}

How the support worker communicates with their patient will play an important part in relaying any fears or anxiety that the patient may have. First impressions really do count and how the patient perceives their care giver through their non-verbal communication is important. Nazarko (2009) states that a person's opinion of someone is $90 \%$ decided upon through non-verbal communication at the very first meeting. As stated by Stonehouse (2014:394) "by always acting in a friendly, open and professional manner will encourage and support our patients in communicating their wishes, feelings, worries and needs."

To discover how the patient is feeling the support worker will need to use a combination of open and closed questions. If closed questions are sorely used then the patient will not be able to express their concerns and worries. By asking open questions the patient is prevented from replying with only one word answers and encouraged to share how they are feeling.

Active listening is also a skill which needs to be developed. We don't just have to listen to our patients but we must actively listen to them. This means focusing on what the patient is saying and not allowing distractions to interfere with our communication. To do this correctly we need to make sure we can devote the necessary time to the patient, or if we can't at that moment to make time as soon as 
we can. Active listening is also about listening to the "music behind the words" (Moss, 2017:6). This is about discovering the real meaning and what is not being said.

The Code of Conduct for Healthcare Support Workers and Adult Social Care Workers in England (Skills for Care and Skills for Health, 2013) states clearly in section 4.1 that you must "communicate respectfully with people" and "in an open, accurate, effective, straightforward and confidential way."

We must also be aware of how the patient is communicating verbally and nonverbally. If they are saying they are fine, do their non-verbal cues support this? If they are asking the same question repeatedly, has their question actually been answered in a way they can understand?

\section{Information Sharing}

There is a common saying that 'fear of the unknown is worse than fear of the known.' Murphy (2013) identify that one of the easiest and effective interventions a support worker can do to reduce stress and anxiety is to provide understandable and useful information to the patient. Successful information sharing will hopefully inform the patient and help to allay their fears, or at least reduce any unfounded fears and anxiety they may have. Information needs to be shared in the most appropriate way. This will require the support worker to know their patient and understand their communication needs. Information needs to be shared at the correct level and amount that the patient requires. Some patients will want to know everything in minute detail, while others may not want to know anything. The patient's wishes in this must be respected. Any written information needs to be in the correct format. Written at a level that is accessible for members of the public and in the patient's first language.

\section{Conclusion.}

So to conclude, this article has highlighted the important role support workers play in recognising and supporting patients who are anxious. It is natural for patients to experience anxiety about their physical and mental condition and the care they are receiving. However there are a number of strategies that are easily employed to help support and reduce this anxiety. Early recognition of the anxious patient and giving them enough time so they can discuss their concerns with the support worker will help. Developing a therapeutic relationship and always acting in the best interests of the patient and involving them in their care as far as they wish to be involved. Communicating in an effective way, including actively listening and sharing information. All these relatively straightforward strategies, if employed will support the patient and enable their experience of health and social care to be more positive and less stressful. Through doing this the support worker will be enabling safe, quality care to be delivered. 
Key Points:

1. It is natural for patients to experience anxiety and stress.

2. This anxiety and stress can be reduced by simply employing a number of strategies.

3. Support workers are key to supporting their patients to reduce their anxiety and stress.

4. Communicating and involving patients in their care will reduce anxiety.

5. Sharing information in a way that is appropriate for the patient is key.

\section{References:}

Askey-Jones S, Askey-Jones R. (2013) The Person With An Anxiety Disorder (569586). In: Norman I, Ryrie I (eds) The Art And Science Of Mental Health Nursing: Principles And Practice. 3rd edn. Open University Press: Maidenhead.

Murphy N. (2013) Stress, Anxiety and Coping (241-260). In: Brooker C, Waugh A. (eds) Foundations of Nursing Practice: Fundamentals of Holistic Care. 2nd edn. Mosby Elsevier: London

Mind (2013) Anxiety and Panic Attacks. https://www.mind.org.uk/informationsupport/types-of-mental-health-problems/anxiety-and-panic-attacks/anxietysymptoms/\#.WqFCieCLSUk (accessed 12 March 2018)

Mitchell M (2005) Anxiety Management in Adult Day Surgery: A Nursing Perspective. John Wiley 7 Sons Ltd: New York

Mitchell M (2011) Contemporary Preoperative and Postoperative Care (155-178). In: Birchenall P, Adams N (eds) The Nursing Companion. Palgrave McMillan: London

Moss B (2017) Communication skills for health and social care. 4th edn. Sage Publications: London

Nazarko L (2009) Advanced communication skills. British Journal of Healthcare Assistants. 3(9): 449-52

Sharples N (2013) Relationship, helping and communication skills (193-218). In: Brooker C, Waugh A (Eds) Foundation of Nursing Practice: Fundamentals of Holistic Care. $2^{\text {nd }}$ edn. Mosby Elsevier: London.

Skills for Care and Skills for Health (2013) Code of Conduct for Healthcare Support Workers and Adult Social Care Workers in England.

http://www.skillsforhealth.org.uk/images/services/code-ofconduct/Code\%20of\%20Conduct\%20Healthcare\%20Support.pdf (accessed 12 March 2018)

Stonehouse D (2014) Communication and the Support Worker. British Journal of Healthcare Assistants. 8(8): 394-397 